\title{
PENGARUH PENGELASAN BESI COR FC DENGAN METODE PREHEAT DAN POST WELD HEAT TREATMENT MENGGUNAKAN ELEKTRODA PADUAN NIKEL
}

\author{
Darul iman $^{1 *}$ dan Helmy Purwanto ${ }^{2}$ \\ ${ }^{1}$ PT. Ganda Makindo, Sayung, Kabupaten Demak, Jawa Tengah \\ ${ }^{2}$ Jurusan Teknik Mesin, Fakultas Teknik, Universitas Wahid Hasyim \\ Jl. Menoreh Tengah X/22, Sampangan, Semarang 50236. \\ *Email: daruli06@gmail.com
}

\begin{abstract}
Abstrak
Dalam pengelasan ada beberapa logam yang mempunyai sifat mampu lasnya kurang baik. Besi cor putih contohnya, ini tidak disarankan untuk di las karena bersifat sangat keras dan tidak mempunyai grafit melainkan hanya besi karbida. Lain halnya dengan besi cor putih, besi cor kelabu termasuk kategori logam yang dapat dilas walaupun sifat mampu lasnya rendah. Besi cor kelabu dapat dilas dengan baik apabila sebelum pengelasan diberi pemanasan mula (preheat) dan setelah pengelasan diberikan postheat atau post weld heat treatmen (PWHT) untu memperlambat laju pendinginan maka dilakukan penelitian dari hasil pengelasan besi cor kelabu atau besi cor FC menggunakan elektroda paduan nikel rendah dengan preheat $600^{\circ} \mathrm{C}$ dan PWHT tujuannya adalah menemukan metode preheat dan PWHT yang baik, dari hasil penelitian didapat, semua spesimen A mengalami retakan kawah, terdapat nilai kekerasan yang kurang seragam pada spesimen A yaitu sebesar 114.75 HRB yang dimana seharusnya kekerasannya melebihi kekerasan pada HAZ spesimen B yaitu 118.75 HRB. Nilai kekersan tertinggi di capai pada spesimen A pada inti las sebesar 120.5 HRB Semakin lama waktu waktu PWHT akan mengurangi perubanan sudut hasil lasan dan semakin bertumbuh struktur ferit mengakibatkan berkurang nilai kekerasannya.
\end{abstract}

Kata kunci: Besi Cor FC, HAZ, preheat, PWHT

\section{PENDAHULUAN}

Dalam prosedur pengelasan tidaklah sederhana, ada beberapa masalah-masalah yang harus diatasi dimana pemecahan masalahnya memerlukan bermacam-macam pengetahuan. Secara terperinci dapat dikatakan bahwa dalam perancangan kontruksi bangunan dan mesin dengan sambungan las, harus direncanakan pula tentang cara pengelasan, cara pemeriksaan, bahan las dan jenis las yang akan digunakan (Wiryosumarto \& Okumura, 2008).

Besi cor kelabu termasuk kategori logam yang dapat dilas walaupun sifat mampu lasnya rendah ini dikarenakan keras, getas dan tidak mampu menahan tegangan akibat siklus termal pengelasan. Berbeda dengan besi cor malleable dan nodular yang memang memiliki sifat mampu las lebih baik, ini dikarenakan besi cor malleable dan nodular relatif lebih ulet dan sulit membentuk struktur martensit sedangkan besi cor kelabu dan besi cor putih sangat mudah membentuk struktur martensit.

Besi cor kelabu dapat dilas dengan baik apabila sebelum pengelasan diberi pemanasan mula (preheat) dan setelah pengelasan diberikan postheat atau post weld heat treatmen (PWHT). Pemilihan logam pengisi atau kawat las yang sesuai juga dapat menjamin keberhasilan pengelasan besi cor kelabu.

\section{METODOLOGI PENELITIAN \\ Bahan}

Besi cor kelabu FC 30, untuk mengetahuinya dilakukan identifikasi struktur mikro dan pengujian kekerasan Elektrode CIN 3 dengan diameter $2.6 \mathrm{~mm}$ dengan spesifikasi seperti pada tabel .

\section{Tabel 1 Komposisi elektrode}

\begin{tabular}{cccccccccc}
\hline $\mathbf{C}$ & $\mathbf{M n}$ & $\mathbf{S i}$ & $\mathbf{S}$ & $\mathbf{P}$ & $\mathbf{C r}$ & $\mathbf{N i}$ & $\mathbf{M o}$ & $\mathbf{N b}$ & $\mathbf{F e}$ \\
\hline 1,7 & 0,5 & 0,30 & 0,1 & 0,01 & 0,05 & 1,4 & 0,01 & 0,001 & $\mathrm{Bal}$ \\
\hline
\end{tabular}

Penelitian ini diawali dengan Pembuatan Kampuh V sudut $60^{\circ}$ jarak celah $1 \mathrm{~mm}$, preheat elektrode $2.6 \mathrm{~mm}$ CIN 3 pada suhu $150^{\circ} \mathrm{C}$ selama 5 menit, posisi pengelasan bawah 
tangan digunakan dalam proses pengelasan dan panjang pengelasan $5 \mathrm{~cm}$. Prosedur pengelasan spesimen A dengan preheat $600^{\circ}$ C tanpa PWHT sedangkan untuk Spesimen B dengan preheat $600^{\circ} \mathrm{C}+\mathrm{PWHT} 600^{\circ} \mathrm{C}$ di tahan 15 menit. Spesimen $\mathrm{C}$ dengan preheat $600^{\circ} \mathrm{C}+$ PWHT $600^{\circ} \mathrm{C}$ di tahan 30 menit. Dilanjutkan dengan pemeriksaan hasil pengelasan dilanjutkan pengujian kekerasan serta pengujian foto mikro

\section{HASIL DAN PEMBAHASAN Logam induk}

Identifikasi struktur mikro dapat dilihat dari struktur grafit dan tipe grafit dapat dilakukan dengan melihat dan membandingkan struktur mikro yang telah di jabarkan menurut ASM Vol.7 pada Gambar 1 sehingga didapat Struktur dan tipe Grafit yang mirip dengan FC 30 dengan struktur perlit dan ferit. Identifikasi sifat mekanis dilakukan dengan menguji kekerasan dengan uji kekerasan Brinnel dengan mengukur lebar pijakan yang kemudian didapat kekuatan tarik sebesar $32 \mathrm{~kg} / \mathrm{mm} 2$, nilai kekuatan tarik sangat mendekati FC 30, sehingga logam induk bisa dikategorikan besi cor FC 30 .

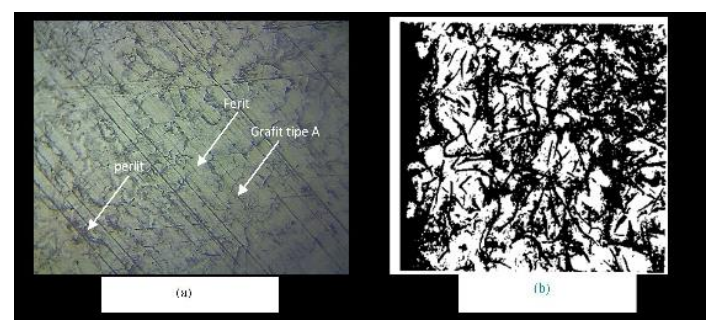

Gambar 1. struktur mikro

(a) Logam induk pembesaran 200x

(b) Besi cor kelabu FC 30 ASM Vol.7

\section{Hasil pengelasan}

Pada gambar 2 spesimen A adalah spesimen yang di las dengan preheat $600^{\circ} \mathrm{C}$ tanpa dilakukan PWHT, spesimen B adalah spesimen yang di las dengan preheat $600^{\circ} \mathrm{C}$ dan dilakukan PWHT $600^{\circ} \mathrm{C}$ ditahan 15 menit dan spesimen $\mathrm{C}$ adalah spesimen yang di las dengan preheat $600^{\circ} \mathrm{C}$ dan dilakukan PWHT $600^{\circ} \mathrm{C}$ ditahan 30 menit. Pada gambar 2 Spesimen $\mathrm{C}$ dapat dilihat bahwa perubahan sudut yang dihasilkan sangat kecil hanya sebesar $1^{\circ}$ kemudian disusul spesimen B dengan perubahan sudut sebesar $1,5^{\circ}$ dan yang paling besar pada spesimen A sebesar $3^{\circ}$ hal ini dapat di simpulkan bahwa semakin lama waktu PWHT di tahan semakin kecil pula perubahan sudut. Pada semua hasil pengelasan spesimen A terdapat retak di bagian tengah ini bisa dikarenakan tegangan sisa yang sangat tinggi, karena jika tegangan yang tersisa adalah tegangan tarik maka hal ini dapat membahayakan konstruksi las, yang mana tegangan tarik tersebut jika melebihi kekuatan tarik akan dapat mengakibatkan retak. (Sonawan \& Suratman, 2006).

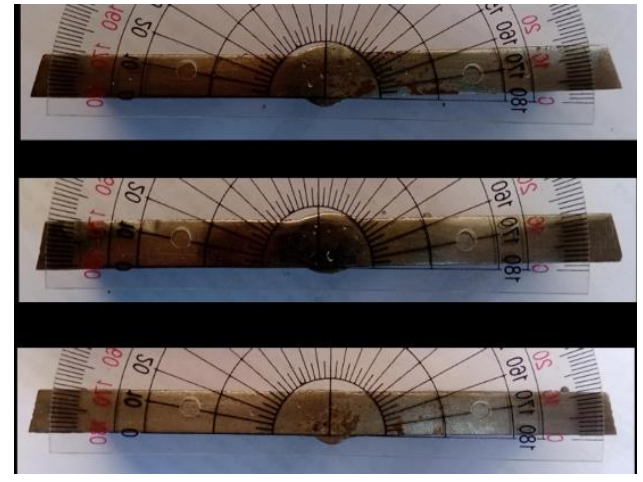

Gambar 2. perubahan bentuk spesimen A, $B$ dan $C$ setelah pengelasan

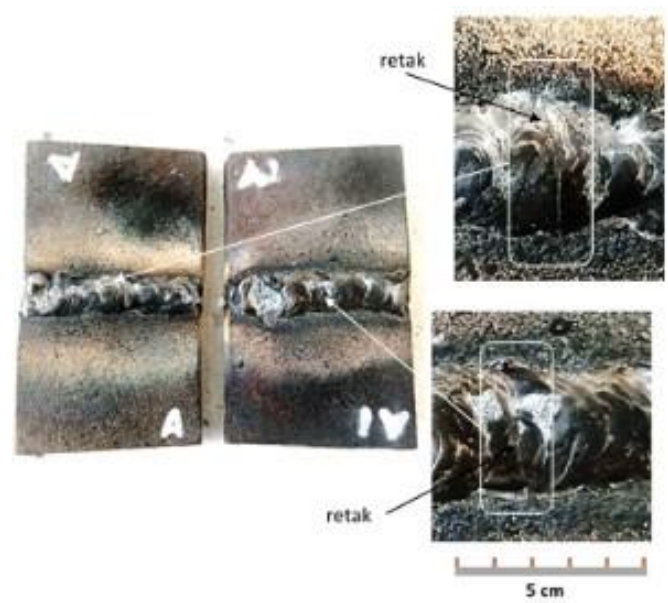

\section{Gambar 3. Hasil pengelasan spesimen A}

\section{Hasil uji kekerasan}

Hasil pengujian kekerasan menggunakan alat uji Rockwell dengan skala kekerasan B dengan identor bola ukuran 1/16 inci dengan pembebanan $100 \mathrm{~kg}$, pengujian dilakukan 2 kali pada setiap spesimen dan melakukan hal sama pada spesimen ke 2, sehingga didapat 4 hasil nilai kekerasan yang 
kemudian di rata-rata dan di sajikan dalam grafik, untuk jelasnya dapat dilihat dalam tabel 2 dan gambar 4.

Tabel 2 Rata-rata uji kekerasan HRB

\begin{tabular}{ccccc}
\hline Spesimen & $\begin{array}{c}\text { Inti } \\
\text { Las }\end{array}$ & HAZ & $\begin{array}{c}\text { HAZ } \\
\text { 4mm }\end{array}$ & $\begin{array}{c}\text { HAZ } \\
\mathbf{1 5 m m}\end{array}$ \\
\hline $\mathrm{A}$ & 120.5 & 114.75 & 103.25 & 103 \\
\hline $\mathrm{B}$ & 118.75 & 118.75 & 103 & 101.75 \\
\hline $\mathrm{C}$ & 118.5 & 109.75 & 102.5 & 101.25 \\
\hline $\begin{array}{c}\text { Logam } \\
\text { induk }\end{array}$ & & & 103.5 & \\
\hline
\end{tabular}

Spesimen A menghasilkan nilai kekerasan rata-rata pada HAZ menurun sebesar 114.75 dan terdapat nilai kekerasan yang tidak wajar yaitu 103 ini tidak sesuai dengan teori dalam buku (Daryanto, 2012) dimana dalam teori tersebut mengatakan bahwa PWHT dapat melunakkan daerah terkena pengaruh las, seharusnya kekerasan pada spesimen A lebih besar dari Spesimen B pada daerah HAZ ini dikarenakan pada spesimen B dilakukan PWHT pada suhu kurang lebih $600^{\circ} \mathrm{C}$ di tahan selama 15 menit, kemungkinan ini dikarenakan adanya retakan pada spesimen A yang tak terlihat pada bagian HAZ sehingga kekerasan menurun akibat kekosongan ruang.

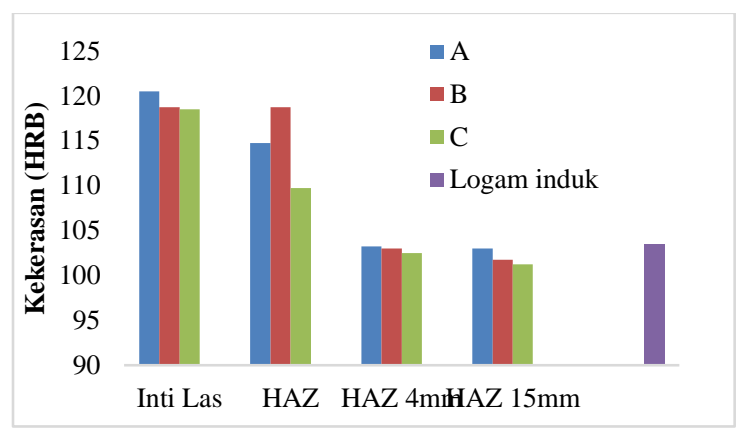

\section{Gambar 4 perbandingan kekerasan}

\section{Hasil foto mikro}

Spesimen A adalah spesimen yang di las dengan preheat $600^{\circ} \mathrm{C}$ tanpa dilakukan PWHT, spesimen B adalah spesimen yang di las dengan preheat $600^{\circ} \mathrm{C}$ dan dilakukan PWHT $600^{\circ} \mathrm{C}$ ditahan 15 menit dan spesimen $\mathrm{C}$ adalah spesimen yang di las dengan preheat $600^{\circ} \mathrm{C}$ dan dilakukan PWHT $600^{\circ} \mathrm{C}$ ditahan 30 menit.

Dilihat Gambar 5 struktur mikro pada semua spesimen didominasi struktur perlit dan sedikit grafit tipe B yang halus terutama pada spesimen A ini paling banyak mengandung struktur perlit, hampir $80 \%$ struktur perlit dan terdapat perlit halus, ini sesuai dengan penelitian (Yaqin \& Muhammad, 2011) dimana banyaknya perlit halus menyebabkan nilai kekerasan tinggi, kemudian di susul pada spesimen B pada Gambar IV. 6 yang dimana struktur ferit mulai terlihat dan mulai menurun kekerasannya, dan yang paling banyak adanya struktur ferit adalah pada spesimen $\mathrm{C}$, ini sangat sesuai dengan teori yang dikatakan (Daryanto, 2012) dimana laju pendinginan yang lama akan menimbulkan struktur perlit bahkan jika pendinginan yang sangat lama bisa didominasi struktur ferit.

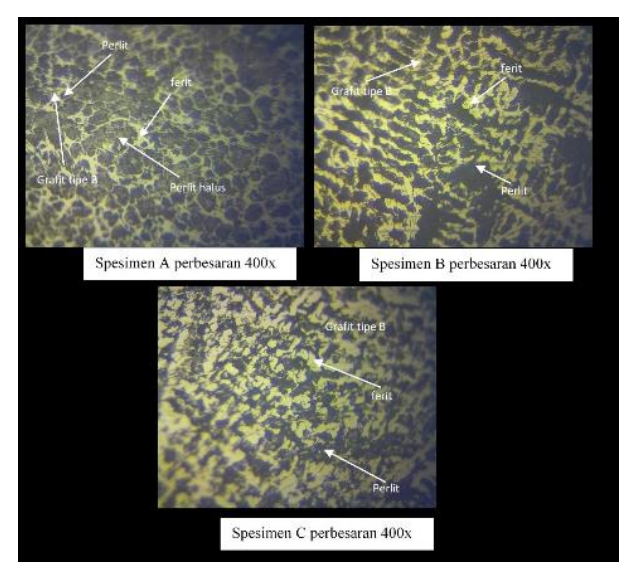

Gambar 5 Struktur mikro Inti las spesimen $A$, B dan C pembesaran 400x

Pada foto mikro daerah HAZ dapat dilihat Gambar 6 ada butir kasar dalam spesimen A dan spesimen B namun pada spesimen $\mathrm{C}$ tidak terlihat, ini sangat sesuai dengan nilai kekerasan dimana terdapat nilai kekerasan pada spesimen A antara 118-120 dan 188-119 pada spesimen B dan pada spesimen $\mathrm{C}$ cenderung turun dengan rata-rata 109.75 dimana pada spesimen A dan spesimen B terdapat butiran kasar dan sifat dari butiran kasar itu cenderung keras dan retak (Daryanto, 2012).

Di daerah pengaruh panas pada logam induk yang berjarak $4 \mathrm{~mm}$ dari HAZ dapat dilihat pada Gambar 7 bahwa spesimen A B dan $\mathrm{C}$ masih terpengaruh, dimana yang awalnya grafit pada logam induk adalah grafit tipe A yang kemudian menjadi tipe $\mathrm{D}$, dan juga jumlah perlit menurun, serta ferit meningkat, 
ini berlaku pada semua spesimen, dan ini juga sesuai dengan teori (Sonawan \& Suratman, 2006) dimana memperlambat laju pendinginan akan menumbuhkan ferit.

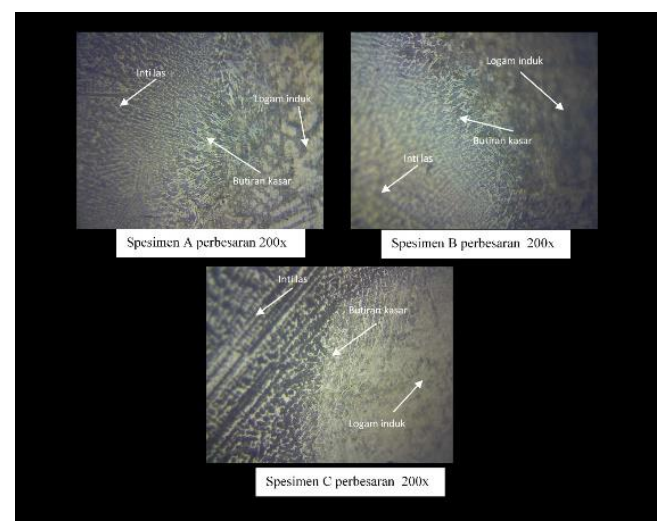

Gambar 6 Struktur mikro HAZ spesimen $A$, B dan C pembesaran 200x

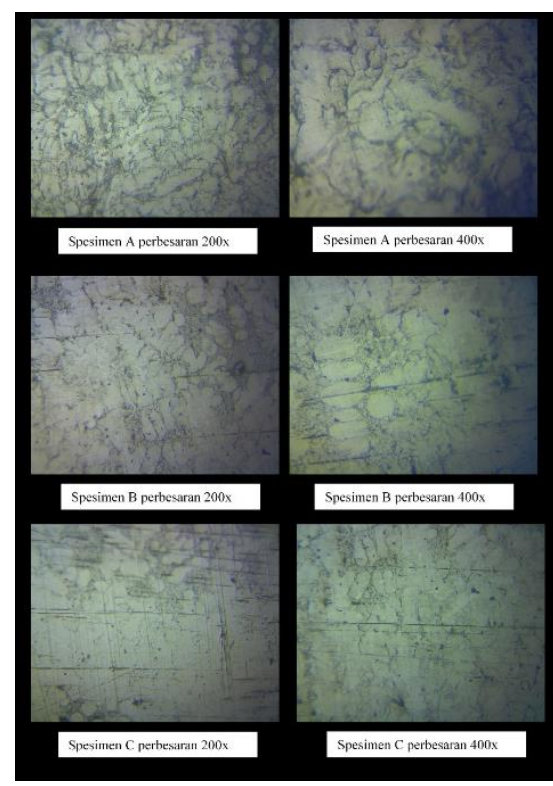

Gambar 7 Logam induk yang berjarak 4 mm dari HAZ spesimen $A$, B dan $C$

Dapat dilihat pada Gambar 8 spesimen A daerah HAZ $15 \mathrm{~mm}$ pembesaran 200x memiliki struktur grafit yang sangat mirip dengan logam induk yaitu grafit serpih tipe A dengan matriks perlit dan ferit, untuk nilai kekerasan yang di hasilkan hampir sama yaitu 103 pada Spesimen A dan103.5 pada logam induk, bisa dikatakan bahwa daerah pengaruh preheat tidak sampai melebihi $15 \mathrm{~mm}$. Pada Gambar IV. 9 spesimen B terlihat adanya pengeruh PWHT dimana berubahnya struktur grafit logam induk pada jarak $15 \mathrm{~mm}$ HAZ dari tipe A menjadi tipe D serta bertambahnya struktur ferit namun struktur perlit juga masih terlihat banyak, bertumbuhnya ferit mengakibat turunnya kekerasan namun keuletan menjadi meningkat, tidak jauh beda dengan spesimen $\mathrm{B}$, spesimen $\mathrm{C}$ juga mengalami berubahnya struktur grafit dari grafit A ke D namun jumlahnya lebih sedikit dibanding spesimen, tak Cuma itu perlit juga berkurang, dan dapat dilihat melebarnya struktur ferit, ini sangat sesuai dengan teori (Sonawan, 2003) dimana laju pendinginan lambat perlahan akan menumbuhkan struktur ferit.

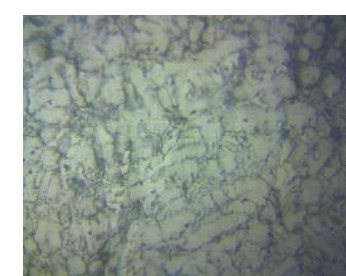

Spesimen A perbesaran 200x

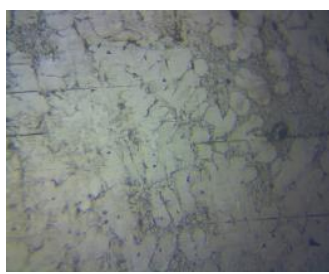

Spesimen B perbesaran 200x

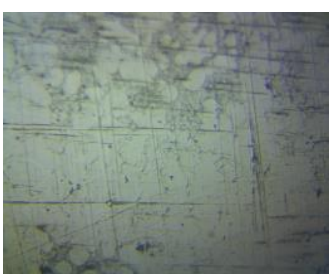

Spesimen C perbesaran 200x

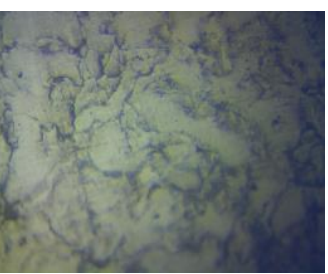

Spesimen A perbesaran $4(x) \times$

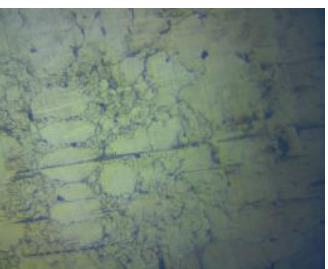

Spesimen B perbesaran $4(x)$.

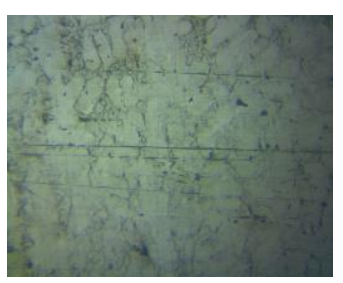

Spesimen C perbesaran 400)
Gambar 8 Logam induk yang berjarak 15 mm dari HAZ spesimen $A$, B dan $C$

\section{PENUTUP}

Kesimpulan

Dari hasil pembahasan didapat kesimpulan sebagai berikut:

1. Semakin lama waktu PWHT akan mengurangi perubahan sudut hasil pengelasan. Besi cor kelabu FC 30 yang di las menggunakan kawat las CIN 3 yang 
tidak di perlakuan PWHT menghasilkan retakan pada semua spesimen

2. Terdapat nilai kekerasan yang kurang seragam pada spesimen A yaitu sebesar 114.75 HRB yang dimana seharusnya kekerasannya melebihi kekerasan pada HAZ spesimen B yaitu 118.75 HRB .Nilai kekerasan tertinggi di capai pada spesimen A pada inti las sebesar $120.5 \mathrm{HRB}$

3. Semakin lama PWHT di tahan semakin bertumbuh struktur ferit dan semakin berkurang nilai kekerasannya.

\section{DAFTAR PUSTAKA}

Daryanto. (2012). Teknik las. Alfabento.

Sonawan, H. (2003). Pengantar Untuk Memahami Proses Pengelasan Logam. Alfabeta, cv. BIODATA PENULIS.

Sonawan, H., \& Suratman, R. (2006). Pengantar Untuk Memahami Proses Pengelasan Logam. Cetakan Kedua.

Wiryosumarto, H., \& Okumura, T. (2008). Teknologi Pengelasan Logam. Jakarta: Pradnya Paramita.

Yaqin, K., \& Muhammad. (2011). Pengaruh Preheat Dan Postheat Terhadap Lebar Haz, Struktur mikro, dan Distribusi Kekerasan Pada Proses Pengelasan SMAW. Jurnal Teknik Material Dan Metalurgi. 